\section{UPDATED LEARNING PROGRAMME ON RADIATION SAFETY}

Health Education England e-Learning for Healthcare (HEE e-LfH) has worked in partnership with the Institute of Physics and Engineering in Medicine (IPEM) to update the e-learning programme on radiation safety for colleagues.

e-RADS supports the information, instruction and training required under Regulation 15(1) of the Ionising Radiations Regulations 2017 (IRR2017), which requires that colleagues who are not closely involved with work involving ionising radiations are to be provided with suitable information to avoid being unnecessarily exposed. It may also provide a useful introductory/refresher resource for trainees and colleagues working in departments using ionising radiations.

The programme identifies the importance of following the safety precautions that are in place to avoid being unnecessarily exposed and covers the basic principles associated with keeping their own exposure as low as reasonably possible.

Each session within the programme lasts approximately 20 to 30 minutes. The $\square$

$\Delta$

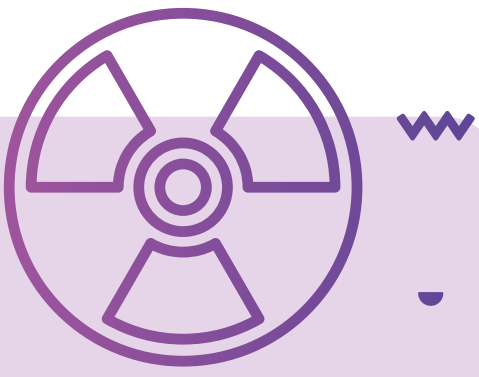

n

$\Delta$

programme comprises the following the topics:

- Radiotherapy, including external beam, brachytherapy and unsealed source therapy

- Diagnostic imaging using X-rays, including planar imaging and fluoroscopy

- Diagnostic and therapeutic nuclear medicine

- Interventional radiology and cardiology.

e-RADS was originally developed for national use, with the support of expert authors within the NHS. In 2020, the programme was revised and updated in partnership with the Institute of Physics and Engineering in Medicine (IPEM) to reflect the requirements of IRR2017 and new technologies and techniques involving the use of ionising radiations in healthcare.

For more information and to access the programme, visit the e-RADS programme page: https://portal.e-lfh.org.uk/Component/ Details/393084.

\title{
BUILDING AN INTERNATIONAL FEDERATION OF DENTAL ASSISTING AND DENTAL NURSING
}

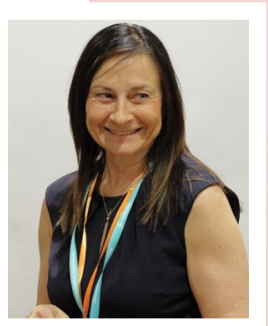

The Canadian Dental Assistants Association, the American Dental Assistants Association and the Society of British Dental Nurses have announced that representatives from their three organisations have been collaborating to establish the first international federation representing dental assistants and dental nurses from around the world.

These three founding partners are looking to formally link national dental assisting/dental nursing professional associations from around the globe in a notfor-profit professional federation called the International Federation of Dental Assisting and Dental Nursing (IFDAN).

The goal of the international group will be to foster leadership and collaboration while acting as the principal advocate and promotor of the dental assisting/dental nursing profession globally. While improving and advancing the profession, the group will also promote global excellence in practice, research, education and will advocate for improved oral health measures/initiatives worldwide.

Over the coming year, the organisations look forward to bringing dental nurses and dental assistants updates on new developments on the work that is being done to create a strong foundation on which to build connectivity among dental assistants/ dental nurses worldwide.

The Society of British Dental Nurses are very proud to join the IFDAN; President Fiona Ellwood BEM (pictured) said: 'This has been a long time in the making and a long time since I presented to other budding members globally. It has been a great honour to walk alongside likeminded people through the pandemic and share events and happenings on a global front. I look forward to the continued work and others joining the Federation'?

\section{BSPD OUTSTANDING INNOVATION AWARD}

Simon Hearnshaw, on behalf of the North Yorkshire and Humber Local Dental Network (LDN), is the winner of the British Society of Paediatric Dentistry's

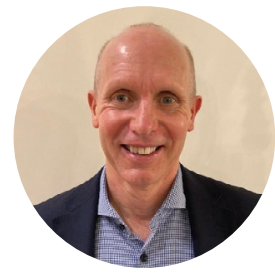
(BSPD's) Outstanding

Innovation Award 2021.

As Chairman of the North Yorkshire and Humber LDN, Dr Hearnshaw (pictured) impressed the judges with the 'In Practice Prevention' (IPP) scheme that ensured thousands more children in the region got access to preventive treatment in a dental practice.

The IPP programme was targeted at deprived areas where oral health need is greatest and at children with the highest levels of disease. A group of dental practices were funded, through a bespoke flexible commissioning approach, to offer more appointments to children.

Health Education England provided training for dental nurses to develop additional skills, such as applying fluoride varnish. The programme treated more than 17,000 children over 2.5 years. Access improved, as did fluoride varnish application rates. There was also a shift of treatment activity towards a more preventive approach.

BSPD's judges said 'With his In Practice Prevention programme working with North Yorkshire and Humber LDN, Simon Hearnshaw addressed BSPD's key aims: improving the oral health of children, reducing oral health inequalities, and upskilling of dental teams to drive up prevention.

'We can see the potential for this initiative to be rolled out nationally and have a longlasting effect. Simon is 2021's worthy winner.'

Dr Hearnshaw said: 'This recognition is shared by all the practices which got on board as well as the brilliant dental nurses who delivered the care, helping to make a difference to thousands of children. Our programme demonstrated that, with the right approach, flexible commissioning works'.

BSPD is delighted by the variety in this year's entries which included Jo Dawson's Raisin Awareness Campaign [featured in $B D J$ Team this March]; the Tooth FaiRead blog from Dayna Rosenthal and Nikita VasriaShah; and Katie Davies' HaBox, a dental product subscription box for children. 